\title{
AGILITY IN CONSUMER RETAIL: SENSE-RESPONSE ALIGNMENT THROUGH THE EYES OF CUSTOMERS
}

\author{
Maura Atapattu \\ Queensland University of Technology \\ m.atapattu@qut.edu.au \\ Darshana Sedera \\ Queensland University of Technology \\ T. Ravichandran \\ Lally School of Management
}

\begin{abstract}
In hyper competition, firms that are agile: sensing and responding better to customer requirements tend to be more successful and achieve supernormal profits. In spite of the widely accepted importance of customer agility, research is limited on this construct. The limited research also has predominantly focussed on the firm's perspective of agility. However, we propose that the customers are better positioned to determine how well a firm is responding to their requirements (aka a firm's customer agility). Taking the customers' stand point, we address the issue of sense and respond alignment in two perspectives-matching and mediating. Based on data collected from customers in a field study, we tested hypothesis pertaining to the two methods of alignment using polynomial regression and response surface methodology. The results provide a good explanation for the role of both forms of alignment on customer satisfaction. Implication for research and practice are discussed.
\end{abstract}

Keywords: Agility, agility alignment, sense and response, u-CRM, polynomial regression

\section{INTRODUCTION}

Agility is emerging as an important determinant of success in contemporary competitive business environments, where achieving sustained competitive advantage is said to be difficult and elusive (Roberts and Grover 2012a; Tallon and Pinsonneault 2011). Firms nowadays are striving towards constant and effective sensing of customer needs and requirements in order to respond to customers in a tailored manner (Atapattu and Sedera 2013b). In other words, sensing essentially provides customer intelligence which can help a firm's responsive actions on unique customer requirements. Hence, firms are investing heavily in a multitude of technological tools and platforms - mobile apps being one of the prominent examples of this. Firms would like their customers to mimic their daily routines of purchasing and purchase considerations through such mobile apps (Lamarre et al. 2012) as with smart functions of smart mobile technology (Shankar et al. 2010), retailers have the potential to dynamically create and launch customer-focused activities with a high degree of precision. As Narayanaswami et al. (2011) noted, Smart devices and applications are heavily influencing the retailing landscape, making global shifts towards 'everywhere - ubiquitous - retailing', and 'everywhere - ubiquitous sensing and responding'.

As per a recent study of key IT and management trends in 2011-2012 customer intelligence gained through smart devices appeared among the top five most influential management technologies 
worldwide (Luftman et al. 2012). In Australia, the two major retailers (Woolworths with 41.1\% of market share and \$48.56 billion revenue, and Coles with 31\% market share and \$34.1 billion revenue in 2012) both launched mobile shopping apps in 2011 with the intent of sensing customer requirements better, by connecting ubiquitously to access their daily routines 24x7 (Atapattu and Sedera 2013a). Thus far, over 3 million customers (1.8 million Woolworths customers and over 1.5 million Coles customers) have downloaded the apps from Android ${ }^{\circledR}$ and Apple ${ }^{\circledR}$ markets which is about $14 \%$ of the Australian population. Consequently, when Woolworths acquired a business intelligence company "Quantium" in 2013 citing the importance of better analyzing the shopping habits of Australians outside its stores (Kohler 2013), Coles recently relaunched its customer loyalty scheme "FlyBuys" with the help of an expert analytics team brought from the UK (Robin 2013).

On the other hand, customers are aware of the 'sensing' in which retailers engage through mobile apps. In return, they expect that the retailers will respond swiftly to their unique requirements (Atapattu and Sedera 2014). So, they expect highly personalized company-to-consumer responses (Kaplan 2012). In other words the customers evaluate how agile a firm towards their unique requirements based on their actual experiences. Whilst there is diversity in consumer mobile apps use; thus, the extent and wider use of the app and adoption of it is of great importance to the retailer. However, failing to provide adequate, efficient and effective responses could lead to low customer satisfaction and disengagement (Choi and Mattila 2008) from the mobile app. As this innovative customer engagement discussed here allows firms to understand customer requirements better (sensing), whilst customers expect that their 'unique' requirements are identified by the retailer (responding). This focused scenario of customer sensing through mobile apps in consumer retail, we argue that customers could effectively judge the responding capacity of the firm. It provides the customers' perspective of firm's agility which is missing in the current notion of agility literature.

This view is unique in a number of different ways. Most studies have observed agility from the firm's perspective, where prior research elucidates two forms of sense-response alignments, namely, matching and mediation, on firm performance from the firm's perspective (Roberts and Grover 2012a). Also, past studies in the management discipline have alluded to the importance of the customer's perspective in firm performance (Kaplan and Norton 1996). Despite the importance of customer perceptions to contemporary firms in dynamic markets, little is known about the firm's customer agility from the customer's viewpoint. In addition, we argue akin to several past studies in marketing and consumer behavior (Gao et al. 2010; Kaplan 2012; Lamarre et al. 2012; Rohm et al. 2012; Shankar et al. 2010) who demonstrated that customers as the users of a mobile app would have a reasonable knowledge of the sensing capabilities of such apps. Therefore, we position that the customers could effectively judge the responding capacity of the firm through their perception of the firm's responsiveness.

The primary objective of this research is to demonstrate the importance of alignment between sensing and responding capabilities in the firm's agility for achieving superior customer satisfaction. In other words, our main premise in this study here is not just to look at the sensing and/or responding capabilities per se but the alignment between the two from the customers' perspective. While past studies have conceptualized agility in terms of structures and processes that enable firms to sense and respond, we take a different viewpoint in this research and seek to examine agility from the customers' perspective. This paper investigates the notion of sense-response misalignment from the customers' point of view in the context ubiquitous customer relationship management through smart mobile apps, which we label as ubiquitous CRM (u-CRM). We introduce the term u-CRM for mobile apps here simply because, the mobile apps we refer in this discussion are a key component of the firm's customer relationship management system which they use to connect with their customers ubiquitously to sense and respond to their customer unique requirements.

Additionally, the agility alignment has never been viewed from the customer's angle. We argue here that, this discussion of customers' perspective of firm's agility is now long overdue. Possibly, there 
could be nuanced ways in which customers experience the firm's ability in aligning sense-response capabilities, which in turn could impact on firm performance. Thus, our second objective is to examine how a firm's customer agility impacts on firm performance. More specifically, how does the alignment between a firm's sensing and responding capabilities impact its performance (through customer satisfaction)?

The paper first defines agility before invoking the importance of understanding the characteristics of firm agility from the customer's standpoint. We then discuss customer agility in light of nomological discussion around other related concepts before developing our theoretical model. Building on this discussion, we then formulate and present our research hypothesis. Then, we describe our empirical research design and the testing of our research model. Finally, we discuss our findings and limitations, implications for both research and practice, and potential future research directions.

\section{THEORETICAL BACKGROUND}

Studies of organizational agility (Haeckel 1999; Nazir and Pinsonneault 2012; Roberts and Grover 2012a; Zaheer and Zaheer 1997) provide the theoretical foundation to this study. Overby et al. (2006) have defined enterprise agility in its broadest sense as the firm's ability to sense environmental change and respond rapidly, with several others defining agility in a similar manner (e.g. Roberts and Grover 2012a), with two common attributes describing it - sense and response (Overby et al. 2006; Roberts and Grover 2012a; Roberts and Grover 2012b; Sambamurthy et al. 2003).

Sensing represents the knowledge component of agility (Overby et al. 2006) and reflects the firm's ability to find appropriate opportunities and/or threats to act upon (Dove 2001). Responding describes the firm's ability to act quickly and accurately on opportunities and/or threats (Dove 2001; Overby et al. 2006). Sense and response explain how firms respond to opportunities and threats with speed, ease and dexterity (Overby et al. 2006). A firm may display its agility in many different areas such as customer-based processes, supply chain interactions, and day-to-day operations (Huang et al. 2012; Roberts and Grover 2012b; Yusuf et al. 1999a).

\section{Alignment of Sensing and Responding}

Researchers argue that sense and response should be aligned (Overby et al. 2006; Roberts and Grover 2012b). These two capabilities (Overby et al. 2006; Roberts and Grover 2012a; Roberts and Grover 2012b) are complementary, yet distinctively different (Roberts and Grover 2012a). As previous studies suggest (Overby et al. 2006; Roberts and Grover 2012a), simply possessing the capabilities of sensing and responding themselves do not lead to competitive advantage.

Sensing and responding alignment provides a well synchronized agile capability whereby a firm is able to detect a breadth of customer-based opportunities that they are able to respond to in a timely and effective manner (Overby et al. 2006). On the other hand, sense-response misalignment can bring about severe consequences (Strandholm et al. 2004), as described in the well-documented Woolworths case study in the 1990s (Roberts and Grover 2012a). Woolworths in the US initially failed to sense the growth of suburbs and the migration of shopping away from the urban centers in which most of the Woolworths stores were located. They also had a mismatch between their merchandise and what their customers, who continued to shop downtown, wanted. Their ultimate attempt to rebrand themselves was too late and ineffective, leading to the demise of all of their US stores by 1997. In another example, the bookstore Borders failed to sense the shift to online retailing in the late 1990s and didn't have the ability to respond once it sensed the shift (Business Week, 3 Apr, 2000, p. 75). The point here is that if a firm is unable to sense in a timely manner, it might be too difficult for them to respond when they need to. Quintessentially, the limitations in responding have to be mitigated through effective sensing. 
The notion of alignment can be represented as one that is "matching" or "mediated" (Overby et al. 2006; Roberts and Grover 2012a; Venkatraman 1989). The matching perspective specifies the theoretically defined match between two related variables (in our discussion, these are sense and response) (Venkatraman 1989). Hence, if the match between the two (sense and response) variables is stronger, and both variables (sensing and responding) score "highly", the greater the effect of customer agility on a relevant criterion variable (Roberts and Grover 2012a). Consequently, the mediation perspective embraces the presence of noticeable intervening mechanisms between an antecedent variable and a dependent variable (Venkatraman 1989). Hence, the mediation perspective provides insights into the sense-response-performance process(Roberts and Grover 2012a). Capturing the mediation perspective from the customer's angle would provide insights into the process senseexperience (customers')-satisfaction. This perspective of viewing the firm's agility through the customer's lens can provide deeper insights into the relationship between agility and firm performance from a different yet important angle.

\section{Agility from Customer's Standpoint}

There are several studies in Information Systems that focus on firms' agility to sense and respond to customers (as opposed to competitors). For example, Roberts and Grover (2012b) defined a firm's customer agility as the "degree to which a firm is able to sense and respond quickly to customer-based opportunities for innovation and competitive action". As mentioned earlier, traditional agility studies in Information Systems research observe agility of the firm by asking the management about the firm's sensing and responding capabilities, that is, by asking managers what they think are their capabilities of sensing and responding.

For example, in a study on market orientation (Narver et al. 2004) and customer agility (Roberts and Grover 2012a; Roberts and Grover 2012b), the questions were directed to the firm's middle management to comment on the sensing abilities of the company. Similarly, the responding capabilities were measured by asking the responding managers about whether they thought the organization was responding adequately to customer demands. In studies like Narver et al. (2004) and (Roberts and Grover 2012b), customer-centricity is implied - yet not measured from the customer point of view. For example, respondents guess the perceived responsiveness of the firm from the point of view of customers. In general, firms are in a better position to understand the amount of sensing, and customers are in a better position to inform us whether the firm is responding to their needs. In the present research, we observe the amount of sensing done through customers' mobile devices. This phenomenon is directly linked with the use of mobile apps (discussed in the 'model development' section of this paper in more detail).

In this discussion, we look at this issue from the customers' point of view, where we define firm's agility as the "degree to which a customer perceives a firm's ability to sense and respond quickly to his/her changing needs and wants". This notion of the customer's perspective of agility is described below in detail.

Sensing customer agility includes scanning, learning and interpreting shifting customer requirements and customer-based opportunities (Rapp et al. 2010; Roberts and Grover 2012a; Teece 2007a), where responsiveness is related to the execution of customer-focused competitive actions through an assembly of a firm's existing processes or services (Jayachandran et al. 2004; Roberts and Grover 2012b; Teece 2007a). Following which, the customers can recognize the firm's responding capabilities to their needs. In other words, a customer's perception about the firm's responsiveness is a valid indicator of the firm's responsiveness. Based on this reasoning, we argue that the customers are well positioned to evaluate firms' customer responsiveness (firms' customer agility). Hence, we suggest that the customerperceived firm responsiveness is an important component in understanding agility. However, the existing research predominantly makes use of the managers of the individual firm to estimate the firm's 
responsiveness (Roberts and Grover 2012b). Our intention here is not to discount the managers' role in assessing the firm's responsiveness, but to highlight the importance of customers' participation in a firm's responsiveness audit. We argue that the understanding of firms' customer agility is incomplete without comprehending firm agility from the customers' standpoint as the organizational perspective provides the internal view of the firm's customer agility, and the proposed customer perspective could provide the much required external view of the firm's customer agility.

In the IS in new paradigm (Ubiquitous-IS), customers are an important group of users. Techno-savvy customers are increasingly making their shopping interactions online in digitized environments using contemporary applications such as u-CRM. Drawing from our example of the use of u-CRM in two of the largest retailers in Australia, we posit that they are constantly and continuously sensing the customer requirements through their engagement with u-CRM. When customers create shopping lists, check fuel prices, and search recipes, products and specials using u-CRM, the organizations are able to get rich insights about individual customer preferences as such activities leave digital information footprints (Chi et al. 2010). The more the customers use the u-CRM, the more opportunities are created for organizations to learn about individual customers. As increased use of u-CRM provides more opportunities for customer sensing, the extent of u-CRM use becomes a proxy for a firm's sensing capability. However, the firm cannot sense their customer needs unless the customers use the application. Hence, in this discussion, we surrogate firm's customer sensing to the degree to which the customers use the u-CRM. Following the customer's use of u-CRM, firms are getting to know more about individual customer preferences, and then the firm is able to respond to the needs of individual customers with ease, speed and deftness, when the firm is agile (Nazir and Pinsonneault 2012; Overby et al. 2006; Roberts and Grover 2012a; Roberts and Grover 2012b). Thus, the customers are able to recognize that the firm is responsive to their individual needs. In other words, customers are able to perceive firm's responding capabilities based on what they actually experience. Customer-perceived firm's responsiveness then influences customer satisfaction.

\section{Research Model, Measurement and Hypotheses Development}

Following the earlier notions of agility alignment (Overby et al. 2006; Roberts and Grover 2012a), we propose a research model (Figure 1) of sensing, responding and customer satisfaction. Underlying the model is the assumption that 'customer satisfaction' will be at its highest when a firm's sensing and responding capabilities are aligned.

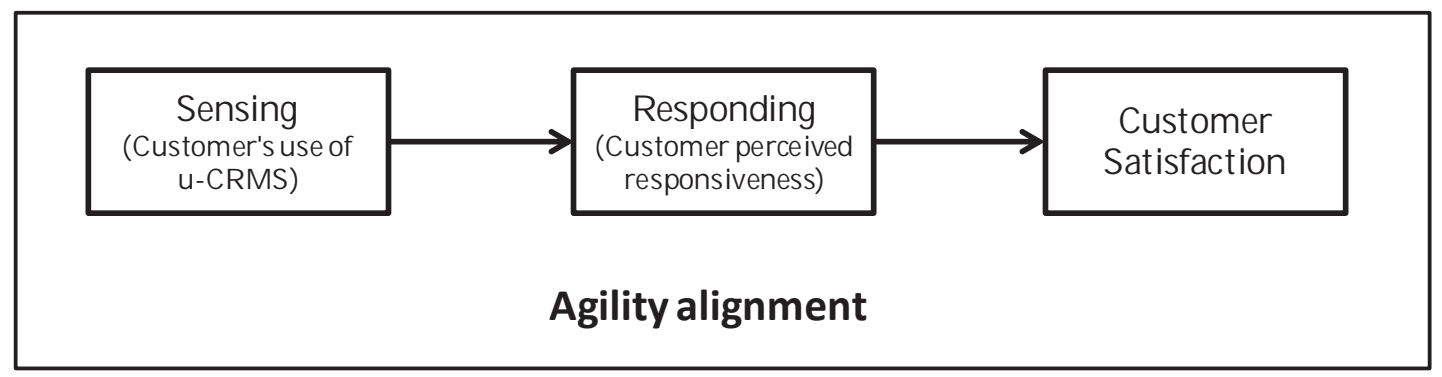

Figure 1: Conceptual Model: Customer's use of ubiquitous mobile-CRM, perceived responsiveness, and customer satisfaction

Based on the argument that increased u-CRM use by customers increases the opportunities for an organization to carry out customer sensing, we conceptualize that the extent to which a customer uses the u-CRM app is a surrogate measure for the firm's sensing in this research. Following the notions of agility alignment (Roberts and Grover 2012a), a firm is now able to execute customer-focused competitive actions based on what they have sensed about their customers through the customers' use of u-CRM. As the firm's responsive actions are based on the intelligence obtained by the firm on what 
customers want through their use of u-CRM, customers are now able to recognize that the firm is responding to their specific requirements through the actual experience they perceive. In other words, a firm's responsiveness is reflected in customer-perceived firm's responsiveness. The actual experience of the customers then determines the level of customer satisfaction, since customers perceive that the firm is responding to their unique requirements. Thus, we propose our conceptual model as above ( Figure 1).

We followed the guidelines recommended by Churchill (1979) for developing the measures of our constructs. We first conducted a literature search on firms' customer agility to specify the domain of the construct (see Appendix A). Following the definition of firms' customer agility, we further reviewed the literature to develop sub-measures and measurement items for each construct of firms' customer agility based on our conception. Following this, we generated sample items based on this literature review and validated measures of similar constructs (e.g..Barki et al. 2007; Bhattacherjee 2001; Jayachandran et al. 2004). Where possible, the existing measures of constructs were adapted to the context of this study. For new measures and those that required significant changes, we followed the standard scale development procedures stipulated in Mackenzie et al. (2011). We then conducted a pretest with a sample of ten fellow researchers some of who were an actual users of mobile apps for shopping and a pilot study comprising of 30 customers who actually uses the mobile shopping apps to assess the reliability and validity of our measures. Our pilot analysis and subsequent follow-up discussion with a subset of respondents provided sufficient confidence in the scales to proceed with the full-scale survey administration of the target sample frame.

Our measures of customer satisfaction and responsiveness have been adopted from (Bhattacherjee 2001) and (Roberts and Grover 2012a), respectively. Although measures for sensing are available from past studies, all of those measures assessed sensing from the organization's point of view. Given our rationale for employing use measures as surrogates of sensing, appropriate measures were identified from Barki et al. (2007); Burton-Jones and Straub (2006) and Venkatesh et al. (2008) where they have either used similar constructs or provided guidelines for developing new measures for similar constructs. Appendix B presents the discussion of the formative/reflective nature of the measures, and Appendix C lists the constructs, items and the sources for all construct measures.

\section{Agility Alignment}

As illustrated in Overby et al. (2006), the agility alignment in general answers the question on whether a firm senses opportunities in areas where it possesses the capabilities to respond, or whether it senses opportunities beyond which the firm is able to respond. Here, the firm is aligned if they seldom waste their capabilities, either by possessing responding capabilities that lie unused or by sensing opportunities that cannot be seized (Overby et al. 2006). In other words, the firm only senses those opportunities to which it can respond, or the firm develops capabilities that are useful only for those opportunities it could sense. In contrast, non-aligned firms may hold responding capabilities that do not apply to the opportunities they sense, or they do not own responding capabilities to support the breadth of opportunities they sense. As discussed above, a firm can sense more, but may choose to only respond to a subset of what it has sensed. Sensing essentially provides intelligence which can help a firm's responsive actions. In this study, we define sensing in terms of the features that firms have provided in the apps. This is a case where a firm might have built capabilities to acquire customer preferences but may not have the capacity to act upon this information. In fact, sensing more could be problematic for firms as customers may raise their expectations and ask for more from the firm.

Prior research on agility alignment (Roberts and Grover 2012a) proposes that a firm's customer agility impacts its performance; but, to gain optimum effect of customer agility on firm performance, the firm needs to align its sensing and responding capabilities (Haeckel 1999; Overby et al. 2006; Teece 2007a). Overby et al. (2006) suggested that the enterprise agility should be measured as a function of its sensing 
and responding capabilities, and they oppose measuring enterprise agility as a direct measurement. In other words, to create an overall measurement, the two capabilities of sensing and responding should be measured individually and separately and then combined to get the actual agility assessment. Therefore, the overall agility score will be dependent on the functional relationship linking the two sensing and responding sub-scores (or the alignment) (Overby et al. 2006). Further, they stated that agility alignment is better described by the degree to which the two sense-response capabilities are aligned in a continuous, rather than a binary scale. The core idea of alignment is not that the firm is merely aligned or non-aligned, but that the alignment is attained somewhere in a continuum between the two.

Alignment in general refers to "the degree to which the needs, demands, goals, objectives, and/or structures of one component are consistent with the needs, demands, goals, objectives, and/or structures of another component" (Nadler and Tushman 1983). As Roberts and Grover (2012a) discussed, in the context of customer agility, alignment refers to the degree to which the structures and objectives of a firm's customer sensing capability should be consistent with the structures and objectives of its customer responding capability. Researchers recommend considering multiple specifications as competing theories or models suggest, when considering the most appropriate perspective of alignment for a given research question (Venkatraman 1989). Roberts and Grover (2012a), for example, studied sense-response alignment with matching and mediation perspectives from firms' perspective with the sense, response and firm performance data obtained from the marketing managers of firms. In this paper, we investigate the alignment between firms' customer sensing capability and customer responding capability in terms of two perspectives, namely, matching and mediation, from the customers' perspective of agility.

\section{Alignment as Matching}

Matching refers to the theoretical match between two related variables wherein the basic tenet is that the stronger the match between customer sensing capability and customer responding capability, the greater the effect of customer agility on an appropriate criterion variable (Overby et al. 2006; Roberts and Grover 2012a). Accordingly, firms are likely to extract greater value from their customer agility when they are aligned in their sensing and responding activities. This is clearly evident in the welldocumented case study of BMW (Roberts and Grover 2012a), as they were able to sense emerging customer needs by involving lead users in the idea generation towards the product innovation activities, and they responded quickly to the new ideas by implementing them in upcoming products. In the context of this discussion, the firm is able to sense emerging customer needs through their use of u$\mathrm{CRM}$, and respond to the changing customer requirements through the targeted customer-based actions.

As proposed by Overby et al. (2006), the agility score for agile firms can be expressed as the minimum of the sensing and responding scores when the two capabilities are in synch (or aligned 100\%). This supports the notion that, while a firm can neither sense nor respond to all opportunities, it is capable of responding to those that it senses (or vice versa):

$$
\text { Enterprise Agility score Aligned = min (Sensing score, Responding score) }
$$

On the contrary, for non-agile firms, the score is calculated as the product of the sensing and responding scores as its sensing and responding capabilities are not in synch. What it shows is that, what the firm senses and what the firm is able to respond to, do not always match up; thereby, limiting the number of opportunities the firm can seize:

\section{Enterprise Agility score ${ }_{\text {Non-Aligned }}=$ Sensing score $\mathrm{x}$ Responding score}

At one extreme, misalignment can cause severe negative consequences (Strandholm et al. 2004). As reported in (Roberts and Grover 2012a), in the case of Woolworths in the US the company initially failed to sense the growth of suburbs and, as a result, its target customer base shifted their shopping 
activities away from the urban centers where most of the company's stores were located. Consequently, the merchandise and the needs of the customers who continued to shop 'downtown' had a mismatch. The subsequent attempts they made towards rebranding the "Woolworths stores" appeared too late and were ineffective at the end, ultimately leading to the closure of all its US-based stores by 1997.

In some cases as documented in the Xerox case (Overby et al. 2006; Roberts and Grover 2012a), some firms are equipped with higher sensing capabilities and are able to sense changes relevant to their line of business, yet lack the responding capability and fail to respond to the opportunities in an agile manner. In the 1970s, Xerox managed to sense the impending changes in the computing industry to develop multiple computing innovations, yet failed to market them. Xerox managed to sense the shifting customer demands, but nonetheless was unable to respond quickly or adequately. Similarly, a firm may have under-developed sensing capabilities yet have well-honed responding capabilities as in the case of Apple's introduction of the Newton (Roberts and Grover 2012a). Apple's decision to position the Newton as a mass-market product was a failure as it was too early in its development to be available as a mass-market product. It lost its audience and never gained momentum in the PDA market in the early 200os. However, Apple subsequently did become the leader in the PDA market with the recent introduction of the iPhone and iPad. In such cases, the firms either sense the wrong opportunities or simply fail to sense the correct opportunities. All these practical cases share the common notion that the consequences of misalignment and alignment of a firm's sensing and responding capabilities could be decisive and extremely critical for their competitive position in the market.

As the extant research affirms (Overby et al. 2006; Roberts and Grover 2012a), conceptually, firms that score highly on both sensing and responding capabilities and are well-aligned are more likely to respond to the right customer-based market opportunities at the right time than their non-aligned, less agile counterparts with low scores on either or both sensing and responding capabilities. As a result, such agile firms will be able to provide positive customer experiences and build positive customer perceptions and customer satisfaction. So, we propose customer agility impacts customer satisfaction; however, the full effect of customer agility on customer satisfaction will take place when a firm's sensing (i.e., identifying changing customer needs and preferences) and responding (i.e., fulfilling changing customer needs and preferences) capabilities are aligned (Haeckel 1999; Overby et al. 2006; Roberts and Grover 2012a; Teece 2007b). Thus, we hypothesize:

H1: Agility alignment is positively related to customer satisfaction, such that firms with high (low) sensing capabilities and high (low) responding capabilities will have more (less) satisfied customers.

\section{Alignment as Mediation}

As explained by Roberts and Grover (2012a), the existence of an intervening mechanism between an antecedent variable and the dependent variable is specifies as the mediation perspective. The main difference visible in the mediation perspective, compared to the matching perspective, is that the mediation view of alignment is anchored to a particular criterion variable (Venkatraman 1989). Hence, while the matching perspective provides insights regarding the combinations of different levels of sense and response capabilities, the mediation perspective provides insights into the sense-responseperformance process (Roberts and Grover 2012a). In the context of this discussion, taking the customers' view on agility into account, the mediation perspective provides insights into the senseresponse-satisfaction process.

Conceptually, the mediation perspective entails looking into how the conception of agility works from a process perspective (Roberts and Grover 2012a). Referring to the dynamic capabilities view, focusing on competitor dynamics, Teece (2007b) elucidated that "a firm's ability to manage competitor threats and to reconfigure itself is dependent upon its investment activity, which is in turn dependent on its ability to sense an opportunity". Further, as Roberts and Grover (2012a) mentioned in their recent study on the sense-response-performance context, a firm's performance is primarily dependent on its ability 
to respond to market opportunities (Hult et al. 2005), which in turn is inherently dependent on the firm's ability to sense the opportunities. However, the superior sensing ability cannot be effectively leveraged for value creation if a firm is weak in its responding capabilities (Overby et al. 2006; Roberts and Grover 2012a). When applied to our study, the ability to sense the continuously shifting customer needs via customers' use of u-CRM cannot be effectively leveraged for more satisfied customers unless the firm is able to create positive customer perceptions through superior customer experiences. Likewise, a stronger customer response capability cannot be effectively leveraged if the firm fails to sense customer-based market opportunities (Roberts and Grover 2012a). When applied to our study, a firm's capability of delivering superior customer experience cannot be effectively leveraged unless the firm is able to sense customer-based opportunities through their use of u-CRM in their shopping engagements. Roberts and Grover (2012a) argued that the firm's customer responding capability mediates the relationship between customer sensing capability and firm performance. When applying this notion to our study context, we argue that the customer-perceived responsiveness mediates the relationship between the firm's ability to sense changing customer preferences (via customers' use of u-CRM) and customer satisfaction. So, we hypothesize:

H2: Firms' customer responding capability mediates the impact of customer sensing capability on customer satisfaction.

\section{RESEARCH METHOD}

\section{Sampling Frame and Characteristics}

We operationalized the study model using data on the customers of two market leading Australian retailers who actually use the u-CRM app in their regular shopping engagements, in order to measure the constructs in our research model. We specifically selected the actual users of u-CRM from either of the two largest Australian retailers, as our objective is to understand the sense-response alignment through the degree to which customers use the u-CRM app and the customer-perceived firm's responsiveness. We administered our anonymous surveys online, with the invitations sent to multiple sources in order to capture a sufficient number of respondents who actually use the u-CRM app in their shopping. Alternatively, an online survey was posted on the user community pages on the social media sites of the two case organizations, in addition to the invitation emails sent to a selected sample of current and potential users of a u-CRM app, comprising of students, faculty members and other staff in one of the leading universities in Australia. Our exercise yielded a total of 128 respondents who actually use the system, for a response rate of 38.9\% (from 329 who actually accessed the URL). Our subsequent screening for missing data left us with 118 usable respondents, as one of the respondents left out data. The demographics of our sample revealed that mostly they were below the age of 45 (44\%), and were male (64\%). A sample size of 118 seems adequate to evaluate our research model using PLS (Barclay et al. 1995a; Chin and Newsted 1999; Falk and Miller 1992; Goodhue et al. 2012).

We used wave analysis (Armstrong and Overton 1977) to assess the impact of non-respondent bias, whereby the respondents were grouped into early and late respondents, and comparisons were made among the respondents' age and gender. Our analysis revealed no significant differences between early and late respondents. Based on our findings, non-response bias does not appear to impact our study.

\section{Testing the Research Model}

Barclay et al. (1995b) stated that an assessment of a measurement model should examine: a) individual measurement item reliability, b) internal consistency, and c) discriminant validity. We used the partial least square (PLS) technique of structural equation modeling in SmartPLS 2.0 software (Ringle et al. 2005) to evaluate our research model and the measurement properties of the customer sensing 
(customer's use of u-CRM app) and customer responding (perceived responsiveness) constructs of our model. PLS allows a researcher to test the psychometric properties of the scales used to measure a variable in a measurement model, and to carry out an estimation of the structural model based on the strength and direction of the relationships between the variables, simultaneously (Xu et al. 2011).

To support individual item reliability, we checked the loadings of the individual measurement items on their intended constructs and compared them against the recommended tolerances of 0.60 or, ideally 0.70, as stipulated in extant research (Barclay et al. 1995b; Chin 1998). All of the measurement items met the recommended tolerance limit of 0.60 , while $86 \%$ met the ideal threshold of 0.70 (see Appendix D). Moreover, as seen in Appendix D, the loadings of a given construct's indicators were higher than the loadings of any other, and the same indicators loaded more highly on their intended construct than on any other, lending support to the discriminant validly. However, as seen in Appendix E, the average variance extracted (AVE) of the latent variable "Perceived Responsiveness" was slightly lower than the correlation between this and the other latent variable "Sensing / Use". Overall, the discriminant and convergent validity of the model were acceptable. Further, we calculated the composite reliability and Cronbach's alpha for each construct to examine the internal consistency of the constructs, and all met the suggested tolerances of $>0.70$ (Fornell and Larcker 1981) (see Appendix E).

We next analyzed the structural model to see the significance and strength of the relationships between the constructs using a PLS model and SmartPLS software. We examined the standardized path coefficients, path significance and variance explained (R2) to test the predictive power of the model. The path between sensing (customer's use of u-CRM) and responsiveness (customer-perceived firm's responsiveness) showed a strong and significant positive relationship $(\beta=0.763, p<0.001)$, with customer's use of u-CRM (sensing) explaining 58.2\% of the variance (R2) in customer-perceived firm's responsiveness (responding).

\section{HYPOTHESES TESTING}

\section{Agility Alignment as Matching}

We used polynomial regression to test the hypothesis involving agility alignment as matching (H1). Our decision to use polynomial regression was mainly influenced by the non-linear and asymmetric nature of the customer satisfaction variable as documented in the marketing literature (Anderson and Sullivan 1993; Cheung and Lee 2009). Further, the use of response surface methodology in the interpretation of the surface created by polynomial regression was influenced by its suitability to interpret the three-dimensional relationship between two independent variables (sensing and responding) with one outcome variable (customer satisfaction). With polynomial regression equations, a researcher is able to perform direct tests of theoretical models relevant to the study of alignment (Edwards 1994; Edwards and Parry 1993; Roberts and Grover 2012a). Following which, we used the polynomial regression equation below to test our first hypothesis, "Agility alignment is positively related to customer satisfaction, such that firms with high (low) sensing capabilities and high (low) responding capabilities will have more (less) satisfied customers":

$$
\begin{aligned}
& \text { Customer satisfaction }=f(\text { Customer sensing*, Customer responding**) } \\
& \mathrm{Z}=\beta 0+\beta 1 \mathrm{CS} *+\beta 2 \mathrm{CR}^{* *}+\beta 3 \mathrm{CS} 2+\beta 4(\mathrm{CS} \times \mathrm{CR})+\beta 5 \mathrm{CR} 2+\mathrm{e}
\end{aligned}
$$

Where, in this study $* \mathrm{CS}=$ Extent to which customer's use of u-CRM, ${ }^{* *} \mathrm{CR}=$ Customer-perceived firm responsiveness. Table 1 summarizes our results. 


\begin{tabular}{|l|l|}
\hline & $\begin{array}{l}\text { Beta coefficient / unstandardized } \\
\text { regression coefficients }\end{array}$ \\
\hline Intercept / constant & 4.954 \\
\hline $\begin{array}{l}\text { Customer sensing capability (CS) } \\
\text { (We surrogate this to customer's use of u-CRM) }\end{array}$ & $0.124^{* *}$ \\
\hline $\begin{array}{l}\text { Customer responding capability (CR) } \\
\text { (We use perceived responsiveness here) }\end{array}$ & $0.698^{*}$ \\
\hline $\mathrm{CS}^{2}$ & -0.026 \\
\hline $\mathrm{CS}^{*} \mathrm{CR}$ & $0.093^{* *}$ \\
\hline $\mathrm{CR}^{2}$ & 0.027 \\
\hline
\end{tabular}

${ }^{*} \mathrm{p}<0.0001,{ }^{* *} \mathrm{p}<0.05$

Table 1. Results of polynomial regression analysis

The response surface methodology (Khuri and Cornell 1987) provides the basis required for testing and interpreting the features of surfaces corresponding to polynomial quadratic regression equations. The combination provides the sophisticated statistical nuance required to examine the extent to which combination of two predictor variables relate to an outcome variable, in particular when the discrepancy (or match) between the two predictor variables is a fundamental consideration (Shanock et al. 2010). Figure 2 depicts a response surface for agility alignment; that is, alignment between sensing (using the surrogate measure of u-CRM use) and responding (through the customer-perceived firm's responsiveness) as it relates to customer satisfaction.

First, we examined the effect of the agreement between two predictor variables - sensing and responding - on the outcome variable - customer satisfaction. As displayed in Figure 2, customer satisfaction is significantly higher and changes in a curvilinear manner when they are aligned (along the line of perfect agreement between sensing and responding; see Point A through to Point B along the solid line on the floor of the graph where $\mathrm{X}=\mathrm{Y}$ and Table 2). Also, the customer satisfaction decreases when the discrepancy between sensing and responding increases (when one moves away to the left or right from the center of the graph along the dotted line; $\mathrm{X}=-\mathrm{Y}$ ) suggesting that the customer satisfaction is peaking when sensing and responding are aligned compared to when they are misaligned. Further, the customer satisfaction is higher when both sensing and responding values are both high (Point A) than when they are both low (Point B). 


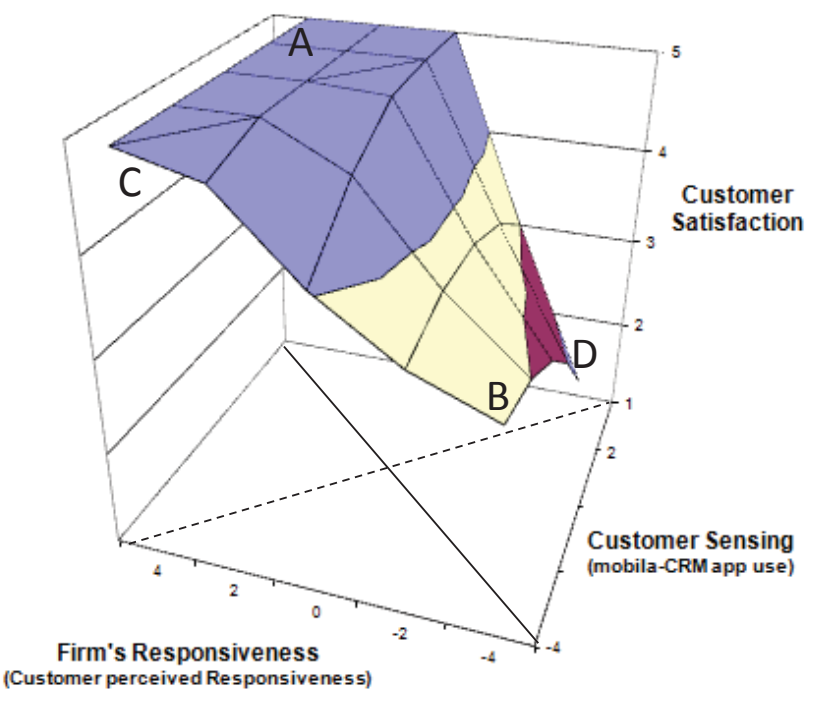

Figure 2: Agility alignment as it relates to customer satisfaction

Next, we examined the two curves; sensing curve (line along B-C) and responding curve (line along BD) against the outcome variable, namely, customer satisfaction. The response curve suggests that the customer satisfaction is greatest when the responding capability reaches medium to higher levels (Point C). However, the sensing curve suggests that the customer satisfaction tapers off when a firm is sensing highly but is deficient in responsiveness (Point D). We then checked the relationship between the direction of discrepancy and customer satisfaction along the line of discrepancy $(X=-Y)$. As the figure displays, the direction of discrepancy is important for customer satisfaction. Satisfaction levels do not suffer as much when the discrepancy is such that perceived responsiveness is higher than customer sensing than vice versa.

\begin{tabular}{|l|l|l|l|l|l|}
\hline Effect & Coefficient & $\begin{array}{l}\text { Standard } \\
\text { Error }\end{array}$ & $\begin{array}{l}\text { Test Statistics } \\
(\mathrm{t})\end{array}$ & p-value & Significance \\
\hline $\begin{array}{l}\text { a1: Slope along } \mathrm{x}=\mathrm{y} \\
(\text { as related to Z) }\end{array}$ & 0.82 & 0.05 & 18.060 & 0.000 & Significant \\
\hline $\begin{array}{l}\text { a2: Curvature on } \mathrm{x}= \\
\mathrm{y}(\text { as related to Z) }\end{array}$ & 0.09 & 0.03 & 3.159 & 0.002 & Significant \\
\hline $\begin{array}{l}\text { a3: Slope along } \mathrm{x}=- \\
\mathrm{y}(\text { as related to Z) }\end{array}$ & -0.57 & 0.09 & -6.278 & 0.000 & Significant \\
\hline $\begin{array}{l}\text { a4: Curvature on } \mathrm{x}= \\
-\mathrm{y}(\text { as related to Z) }\end{array}$ & -0.09 & 0.05 & -1.824 & 0.071 & \\
\hline
\end{tabular}

Table 2: Testing slopes and curves

\section{Agility Alignment as Mediation}

Having established the overall level of consensus as regards to the sense-response alignment in agility as a match between the two capabilities, the analysis now focuses on the mediating effect of alignment in customer satisfaction. As Roberts and Grover (2012a) stated, the notion of agility alignment as mediation in general entails that the effect of customer sensing capability on firm performance is mediated by firms' customer responding capability. Agility alignment as mediation in this discussion, 
taking the customer's perspective into account, essentially refers to the effect of firms' customer sensing capability (through the customer's use of u-CRM) on customer satisfaction being mediated by customer-perceived firm's responsiveness. We first followed the several regression analysis approach suggested by Baron and Kenny (1986). Here we test the effect of the independent variable (sensing) on the dependent variable (satisfaction) with and without the mediating variable (responsiveness) and compare the significance of the coefficients at each step. As depicted in Table 3, the results of the three regressions support the idea of agility alignment as mediation in delivering customer satisfaction.

\begin{tabular}{|l|l|l|l|l|}
\hline Test & $\mathrm{R}^{2}$ & Adjusted $\mathrm{R}^{2}$ & Std. error & $\begin{array}{l}\text { Significance of } \\
\text { Change }\end{array}$ \\
\hline Sensing-Responsiveness & 0.516 & 0.512 & 0.94073 & 0.000 \\
\hline Sensing-Satisfaction & 0.585 & 0.581 & 0.88148 & 0.000 \\
\hline $\begin{array}{l}\text { Responsiveness- } \\
\text { Satisfaction }\end{array}$ & 0.795 & 0.793 & 0.61963 & 0.000 \\
\hline
\end{tabular}

Table 3: Results of the regression analysis

However, the examination of coefficients approach has one limitation as it never really tests the significance of the indirect pathway (Roberts and Grover 2012a). To address this limitation, we performed mediation analysis following Sobel's (1982) product of coefficients approach using SmartPLS 2.0 software (Ringle et al. 2005). This approach calculates the indirect effect and tests for its significance (Roberts and Grover 2012a). In other words, the regression coefficient for the indirect effect signifies the change in the outcome variable (customer satisfaction) for every unit change in the independent variable (sensing) that is mediated by the intervening variable (perceived responsiveness). Our results demonstrate that customer-perceived firm's responsiveness mediates the relationship between firm's customer sensing capability and customer satisfaction (Sobel test statistic $=10.644$, $\mathrm{p}<0.001$ ). The direct effect between the independent variable and dependent variable decreases from 0.765 to 0.257 yet with t-statistics greater than $1.96(\mathrm{t}=4.676)$; hence, the mediation is described as a partial mediation.

\section{CONCLUSION}

In this study we conceptualized and empirically tested a research model that views a firm's customer agility in relation to customer satisfaction. In particular, our conceptualization of firms' agility takes the view of the customers where we investigate the relationship of a firm's agility to its customer satisfaction (as an indicator of firm performance). Broadly speaking, our empirical analysis finds that a firm's agility is significantly related to customer satisfaction. Specifically, the alignment between firms' ability to sense their customers' needs and firms' responding capability (in the form of perceived responsiveness) impacts customer satisfaction, in two distinct ways.

In the conceptualization of agility alignment as matching and mediating, both show significant relationships with customer satisfaction. When taking the matching perspective, our study highlights that customer satisfaction is higher when the customer sensing capability and customer-perceived firm's responsiveness (responding capability) are aligned than when they are misaligned. Additionally, the customer satisfaction is higher when firm's sensing and responding capabilities are higher than when they both are low. When considering the independent effects, 1) customer satisfaction is greatest when customer-perceived responsiveness (responding capability) is at its maximum, whilst 2) customer satisfaction is higher when sensing is low as it tapers off when a firm is sensing highly but is deficient 
in responsiveness. This implies that a combination of high customer sensing capability and high customer responding capability is the way to deliver customer satisfaction and achieve firm performance whilst there is no value in just sensing the customer-based opportunities unless the firm is able to respond to them. Further, our analysis reveals that the direction of discrepancy between sensing and responding capabilities (we refer to the customer-perceived firm's responsiveness here) is important for customer satisfaction where the discrepancy is such that perceived responsiveness is higher than customer sensing than vice versa.

Additionally, our analysis of sense-response alignment as mediation reveals that indeed the customerperceived firm's responsiveness partially mediates the relationship between sensing and customer satisfaction. Our finding supports the prior research on the sense-response-performance relationship view (Hult et al. 2005; Roberts and Grover 2012a; Roberts and Grover 2012b). To put it differently, a firm may sense customer requirements better with superior sensing capabilities yet it needs to respond to such requirements quickly, effectively and adequately in order to make customers happy and convert the firm's superior customer sensing capability into firm performance. Hence, we argue that at least minimal customer responsiveness is still a key to firm performance, despite having a superior customer sensing capability.

\section{Limitations of the study}

Our use of u-CRM as the context limited our ability to fully understand how a firm develops and leverages its overall ability to sense and respond to its advantage in delivering customer satisfaction and achieving superior firm performance. As the constant advancements of mobile technology, the nature of mobile applications, their interactivity and their use in the organizational context poses many challenges for developing meticulous measures, future research should develop more rigorous measures of how firms leverage such technological advancements and tools to achieve superior customer agility via sensing and responding capabilities.

\section{Implications for Research and Practice}

Our study has a number of implications for both research and practice. First, we isolated key attributes and characteristics discussed in previous conceptions of agility and then conceptualized the notion of agility from the customers' point of view. Hence, we suggest that future research could consider the attributes and characteristics we summarized when conceptualizing firms' agility from the customers' perspective. Additionally, we took two perspectives of agility alignment, namely, matching and mediation, and tested them from the customers' perspective, but no comprehensive investigation was made on the ways in which the sensing and responding capabilities could or should be aligned. Following which, we suggest future researchers could take multiple perspectives into account when investigating agility-related phenomena. Regarding the implications for practice, our empirical investigation suggests that firms should align their sensing and responding capabilities in order to achieve business benefits and sustained competitive advantage. We suggest organizations place equal emphasis on nurturing sensing capabilities and on nurturing responding capabilities, in addition to configuring and organizing themselves in order to align the two capabilities.

\section{Contributions}

This study addressed the issue of agility alignment from customers' standpoint to add more detail to the agility construct by introducing the missing customer perspective to the extant body of literature. Our approach reflects the current management thinking as it highlights the importance of customer perceptions in today's hypercompetitive business environment. As the customers' perspective of agility was absent in the extant body of agility literature this study provide a foundation for the nomological network around customers' perspectives of agility. Also, we hope that this study contributes to the cumulative progress of agility related phenomena. In addition we made methodological contributions 
for research, by relaxing the traditional linearity assumptions and demonstrating that in doing so it is possible to uncover complex interactions between the constructs in a research model.

\section{Future Research}

We believe that this study adds more detail to the agility construct by introducing the missing customer perspective to the extant body of literature. It reflects the importance of customer perceptions in today's hypercompetitive business environment. However, in order to understand this critical, yet underinvestigated perspective, and to build on this work, far more research is required on the nomological network around customers' perspectives of agility. Now that we have investigated firms' agility from the customers' perspective using the contemporary u-CRM context, future research may extend this work to the other relevant contexts such as supply chain agility and operational agility in order to further investigate customers' view of organizational agility. Additionally, as we argue that the customers could effectively judge the firm's responding capacity through their perception of the firm's responsiveness, similar approaches are possible in number of other contexts. For example, evaluation of both online and off-line course delivery by university professors can be performed through students' perceptions as they are better positioned to make valid and reliable judgments.

As we have relaxed the traditional linearity assumptions and demonstrated that in doing so it is possible to uncover complex interactions between the constructs in a research model, we suggest future researchers to relax the linearity assumptions to consider non-linear analytical methods such as three dimensional modeling techniques, polynomial regression and response surface methodology, specifically when they use theoretical viewpoints that suggest non-linear relationships.

\section{REFERENCES}

2000. "Can Borders Turn the Page?," in: Business Week. p. 75.

Anderson, E.W., and Sullivan, M.W. 1993. "The Antecents and Consequences of Customer Satisfaction for Firms," Marketing Science (12), pp. 125-143.

Armstrong, J.S., and Overton, T.S. 1977. "Estimating Nonresponse Bias in Mail Surveys," Journal of Marketing Research (14:3), pp. 396-402.

Atapattu, M., and Sedera, D. 2013a. "Agility of the Firm: Customers' Perspective," European Conference on Information Systems (ECIS), Utrecht, Netherlands AIS.

Atapattu, M., and Sedera, D. 2013b. "Agility: Customers' Perspective," Pacific Asia Conference on Information Systems (PACIS), Jeju Island, South Korea: AIS.

Atapattu, M., and Sedera, D. 2014. "Mobile Digital Connectedness: Conceptualization, Measurement and Application," The Second AIS-Journals Joint Author Workshop in PACIS., Chengdu, China.

Barclay, D., Higgins, C., and Thompson, R. 1995a. "The Partial Least Squares (Pls) Approach to Causal Modeling: Personal Computer Adoption and Use as an Illustration," Technology Studies (2:2), pp. 285-309.

Barclay, D., Higgins, C., and Thompson, R. 1995b. "The Partial Least Squares (Pls) Approach to Causal Modelling: Personal Computer Adoption and Use as an Illustration," Technology Stusies (2:2), pp. 285-324.

Barki, H., Titah, R., and Boffo, C. 2007. "Information System Use-Related Activity: An Expanded Behavioral Conceptualization of Individual-Level Information System Use," Information Systems Research (18:2), pp. 173-192. 
Barkin, S.R., and Dickson, G.W. 1977. "An Investigation of Information Systems Utilization," Information \& Management (1:1), pp. 35-45.

Baron, R.M., and Kenny, D.A. 1986. "The Moderator-Mediator Variable Distinction in Social Psychological Research: Conceptual, Strategic, and Statistical Considerations," Journal of Personality and Social Psychology (51:6), pp. 1173-1182.

Bhattacherjee, A. 2001. "Understanding Information Systems Continuance: An ExpectationConfirmation Model," MIS Quarterly (28:2), pp. 229-254.

Burton-Jones, A., and Gallivan, M.J. 2007. "Toward a Deeper Understanding of System Usage in Organizations: A Multilevel Perspective," MIS Quarterly (31:4), pp. 657-679.

Burton-Jones, A., and Straub, D.W. 2006. "Reconceptualizing System Usage: An Approach and Empirical Test," Information Systems Research (17:3), pp. 228-246.

Cheung, C.M.K., and Lee, M.K.O. 2009. "User Satisfaction with an Internet-Based Portal: An Asymmetric and Nonlinear Approach," Journal of the American Society for Information Science and Technology (60:1), pp. 111-122.

Chi, L., Ravichandran, T., and Andrevski, G. 2010. "Information Technology, Network Structure, and Competitive Action," Information Systems Research (21:3), pp. 543-570,655,657.

Chin, W.W. 1998. "The Partial Least Squares Approach for Structural Equation Modelling," in Modern Methods for Business Research, G.A. Marcoulides (ed.). Mahwah, NJ: Lawrence Erlbaum, pp. 295-336.

Chin, W.W., and Newsted, P.R. 1999. "Structural Equation Modeling Analysis with Small Samples Using Partial Least Squares," in Statistical Strategies for Small Sample Research, R. Hoyle (ed.). Newbury Park, CA: Sage Publications, pp. 307-341.

Choi, S., and Mattila, A.S. 2008. "Perceived Controllability and Service Expectations: Influences on Customer Reactions Following Service Failure," Journal of Business Research (61:1), 1//, pp. 24-30.

Churchill, G.A. 1979. "A Paradigm for Developing Better Measures of Marketing Constructs," Journal of Marketing Research (16:1), pp. 64-73.

Dove, R. 2001. Response Ability: The Language, Structure, and Culture of the Agile Enterprise. Wiley.

Edwards, J.R. 1994. "The Study of Congruance in Organizational Behavior Research: Critique and a Proposed Alternative," Organizational Behavior and Human Decision Processes (58:1), pp. 51100.

Edwards, J.R., and Parry, M.E. 1993. "On the Use of Polynomial Regression Equations as an Alternative to Difference Scores in Organizational Research," Academy of Management Journal (36:6), pp. 1577-1613.

Falk, R.F., and Miller, N.B. 1992. A Primer for Soft Modeling. Akron, OH: University of Akron Press.

Fornell, C., and Larcker, D.F. 1981. "Evaluating Structural Equation Models with Unobservable Variables and Measurement Error," Journal of marketing research), pp. 39-50.

Gao, T.T., Sultan, F., and Rohm, A.J. 2010. "Factors Influencing Chinese Youth Consumers' Acceptance of Mobile Marketing," Journal of Consumer Marketing (27:7), pp. 574-583.

Goodhue, D.L., Lewis, W., and Thompson, R. 2012. "Does Pls Have Advantages for Small Sample Size or Non-Normal Data?," MIS Quarterly (36:3), pp. 981-A916.

Haeckel, S.H. 1999. Adaptive Enterprise: Creating and Leading Sense-and-Respond Organizations. Boston: Harvard Business School Press. 
Huang, P.-Y., Ouyang, T.H., Pan, S.L., and Chou, T.-C. 2012. "The Role of It in Achieving Operational Agility: A Case Study of Haier, China," International Journal of Information Management (32), pp. 294-298.

Hult, G.T.M., Ketchen, D.J., and Slater, S.F. 2005. "Market Orientation and Performance: An Integration of Disparate Approaches " Strategic Management Journal (26 12), pp. 1173-1181.

Jayachandran, S., Hewett, K., and Kaufman, P. 2004. "Customer Response Capability in a Sense-andRespond Era: The Role of Customer Knowledge Process," Journal of Academy of Marketing Science (32:3), pp. 219-233.

Kaplan, A.M. 2012. "If You Love Something, Let It Go Mobile: Mobile Marketing and Mobile Social Media 4x4," Business Horizons (55:2), 3//, pp. 129-139.

Kaplan, R.S., and Norton, D.P. 1996. "The Balanced Score Card: Translating Strategu into Action." Boston, Mass: Harvard Business School Press.

Khuri, A.I., and Cornell, J.A. 1987. Response Surfaces: Designs and Analyses. New York: Marcel Dekker.

Kohler, A. 2013. "Woolworths Invests \$20m in Data Analytics." Retrieved 17/7/2013, from http://www.businessspectator.com.au/news/2013/5/2/information-technology/woolworthsinvests-20m-data-analytics

Kohli, A.K., Jaworski, B.J., and Kumar, A. 1993. "Markor: A Measure of Market Orientation," Journal of Marketing Research (4:30), pp. 467-477.

Lamarre, A., Galarneau, S., and Boeck, H. 2012. "Mobile Marketing and Consumer Behaviour Current Research Trend," International Journal of Latest Trends in Computing (3:1).

Luftman, J., Zadeh, H., S., Derksen, B., Santana, M., Rigoni, E.H., and Huang, Z. 2012. "Key Information Technology and Management Issues 2011-2012: An International Study," Journal of Information Technology (27:3), p. 198.

Mackenzie, S.B., Podsakoff, P.M., and Podsakoff, N.P. 2011. "Construct Measurement and Validation Procedures in Mis and Behavioral Research: Integrating New and Existing Techniques," MIS quarterly (35:2), pp. 293-334.

McLean, E., and Sedera, D. 2010. "The Measurement of Information System Use: Preliminary Considerations," AMCIS 2010 Proceedings (255).

Nadler, D., and Tushman, M. 1983. "A General Diagnostic Model for Organizational Behavior: Applying a Congruence Perspective," in Editors Perspectives on Behavior in Organizations, J.R. Hackman, E.E. Lawler and L.W. Porter (eds.). New York: McGraw-Hill, pp. 112-124.

Narayanaswami, C., Kruger, A., and Marmasse, N. 2011. "Pervasive Retail," Pervasive Computing (11), pp. 1536-1268.

Narver, J.C., Slater, S.F., and MacLachlan, D.L. 2004. "Responsive and Proactive Market Orientation and New-Product Success," Journal of Production Innovation Management (21:5), pp. 334-347.

Nazir, S., and Pinsonneault, A. 2012. "It and Firm Agility: An Electronic Integration Perspective," Journal of the Association for Information Systems (13:3), pp. 150-171.

Overby, E., Bharadwaj, A., and Sambamurthy, V. 2006. "Enterprise Agility and the Enabling Role of Information Technology," European Journal of Information Systems (15:2), pp. 120-131.

Po-An Hsieh, J.J., Rai, A., and Xin Xu, S. 2011. "Extracting Business Value from It: A Sensemaking Perspective of Post-Adoptive Use," Management Science (57:11), pp. 2018-2039.

Rapp, A., Trainor, K.J., and Agnohotri, R. 2010. "Performance Implications of Customer-Linking Capabilities: Examining the Complementary Role of Customer Orientation and Crm Technology," Journal of Business Research (63:11), pp. 1229-1236. 
Ringle, C., Marc/Wende, and Sven/Will, A. 2005. "Smartpls," in: 2.0 (beta). Hamburg, Germany: http://www.smartpls.de.

Roberts, N., and Grover, V. 2012a. "Investigating Firm's Customer Agility and Firm Performance: The Importance of Aligning Sense and Respond Capabilities," Journal of Business Research (65:5), pp. 579-585.

Roberts, N., and Grover, V. 2012b. "Leveraging Information Technology Infrastructure to Facilitate a Firm's Customer Agility and Competitive Activity: An Empirical Investigation," Journal of Management Information Systems (28:4), pp. 231-270.

Robin, M. 2013. "Australian Companies "Starting to Get” Big Data as Woolworths Buys Stake in Data Analytics Firm Quantium " Retrieved 17/07/2013, 2013, from http://www.smartcompany.com.au/retail/055358-australian-companies-starting-to-get-bigdata-as-woolworths-buys-stake-in-data-analytics-firm-quantium.html

Rohm, A.J., Gao, T., Sultan, F., and Pagani, M. 2012. "Brand in the Hand: A Cross-Market Investigation of Consumer Acceptance of Mobile Marketing," Business Horizons (55:5), 9//, pp. 485-493.

Sambamurthy, V., Bharadwaj, A., and Grover, V. 2003. "Shaping Agility through Digital Options: Reconceptualizing the Role of Information Technology in Contemporary Firms," MIS Quarterly (2:27), pp. 237-263.

Shankar, V., Venkatesh, A., Hofacker, C., and Naik, P. 2010. "Mobile Marketing in the Retailing Environment: Current Insights and Future Research Avenues," Journal of Interactive Marketing (24:2), 5//, pp. 111-120.

Shanock, L., Baran, B., Gentry, W., Pattison, S., and Heggestad, E. 2010. "Polynomial Regression with Response Surface Analysis: A Powerful Approach for Examining Moderation and Overcoming Limitations of Difference Scores," Journal of Business and Psychology (25:4), 2010/12/01, pp. 543-554.

Slater, S.F., and Narver, J.C. 2000. "Intelligence Generation and Superior Customer Value," Journal of Academy of Marketing Science (28:1), pp. 120-127.

Sobel, M.E. 1982. "Asymptotic Confidence Intervals for Indirect Effects in Structural Equation Models," Sociological Methodology (13), pp. 290-312.

Strandholm, K., Kumar, K., and Subramanian, R. 2004. "Examining the Interrelationships among Perceived Environmental Change, Strategic Response, Managerial Characteristics, and Organizational Performance. ," Journal of Business Research (57:1), pp. 58-68.

Tallon, P.P., and Pinsonneault, A. 2011. "Competing Perspectives on the Link between Strategic Information Technology Alignment and Organizational Agility: Insights from a Mediation Model," MIS Quarterly (35:2), pp. 463-486.

Teece, D. 2007a. "Explicating Dynamic Capabilities: The Nature and Microfoundations of (Sustainable) Enterprise Performance," Strategic Management Journal (28:13), pp. 1319-1350.

Teece, D.J. 2007b. "Explicating Dynamic Capabilities: The Nature and Microfoundations of (Sustainable) Enterprise Performance," Strategic Management Journal (28:13), pp. 1319-1350.

Venkatesh, V., Brown, S.A., Maruping, L.M., and Bala, H. 2008. "Predicting Different Conceptualizations of System Use: The Competing Roles of Behavioral Intention, Facilitating Conditions, and Behavioral Expectation," MIS Quarterly (32:3), pp. 483-502.

Venkatesh, V., Morris, M.G., Davis, G.B., and Davis, F.D. 2003. "User Acceptance of Information Technology: Toward a Unified Theory View," MIS Quarterly (27:3), pp. 425-478.

Venkatraman, N. 1989. "The Concept of Fit in Strategy Research: Towards Verbal and Statistical Correspondence," Academy of Management Review (14:3), pp. 423-444. 
Vodanovich, S., Sundaram, D., and Myers, M. 2010. "Digital Natives and Ubiquitous Information Systems," Information Systems Research (21:4), p. 711.

Xu, J.D., Benbasat, I., and Cenfetelli, R. 2011. "The Effects of Service and Consumer Product Knowledge on Online Customer Loyalty," Journal of the Association for Information Systems (12:11), p. 1.

Yusuf, Y.Y., Sarhadi, M., and Gunasekaran, A. 1999b. "Agile Manufacturing:: The Drivers, Concepts and Attributes," International Journal of Production Economics (62:1), pp. 33-43.

Zaheer, A., and Zaheer, S. 1997. "Catching the Wave: Alertness, Responsiveness and Market Influence in Global Electronic Networks," Management Science (43:11), pp. 1493-1509. 


\begin{tabular}{|c|c|}
\hline \multicolumn{2}{|l|}{ Appendix A: Definitions of Organizational Agility } \\
\hline Definition & Source \\
\hline $\begin{array}{l}\text { Firm's profitable comprehensive response to the business challenges in faced in } \\
\text { rapidly changing, continually fragmenting, global markets for customer- } \\
\text { configured, high-quality goods and services. }\end{array}$ & Goldman et al. (2007) \\
\hline $\begin{array}{l}\text { The business' ability to change and adapt quickly in response to rapidly changing } \\
\text { environmental conditions. }\end{array}$ & Bititci et al. (2000) \\
\hline $\begin{array}{l}\text { Firm's ability to cope up unexpected external changes, ability to convert and take } \\
\text { them as opportunities, and survival ability on unprecedented threats posed by the } \\
\text { environment. }\end{array}$ & Sharifi and Zhang (2004) \\
\hline $\begin{array}{l}\text { Business' ability to grow and respond quickly in a continuously and } \\
\text { unexpectedly changing, competitive market where the value of products and } \\
\text { services is driven by customers. }\end{array}$ & Yusuf et al. (2004) \\
\hline $\begin{array}{l}\text { Organizational ability to thrive in a constantly changing, unpredictable } \\
\text { environment. }\end{array}$ & Day (2011) \\
\hline $\begin{array}{l}\text { Firm's ability to sense opportunities and seizing them by assembling requisite } \\
\text { knowledge, assets, and relationships with speed and dexterity. }\end{array}$ & Sambamurthy et al. (2003) \\
\hline Firm's ability to sense environmental changes and respond readily. & Overby et al. (2006) \\
\hline $\begin{array}{l}\text { Organization's ability to discover new opportunities for competitive advantage, } \\
\text { tie together the assets, knowledge and relationships to seize them, and adopt } \\
\text { abrupt changes in business environment. }\end{array}$ & Setia et al. (1977) \\
\hline $\begin{array}{l}\text { The ability to sense and respond to opportunities and threats with ease, speed, } \\
\text { and dexterity. }\end{array}$ & $\begin{array}{l}\text { Nazir and Pinsonneault } \\
(2012)\end{array}$ \\
\hline $\begin{array}{l}\text { Ability of the firm to sense and respond quickly to customer-based opportunities } \\
\text { for innovation and competitive action. }\end{array}$ & Roberts and Grover (2010) \\
\hline
\end{tabular}

\section{Appendix B: Formative and Reflective Nature of the Constructs}

\begin{tabular}{|c|c|c|c|c|c|c|c|c|}
\hline 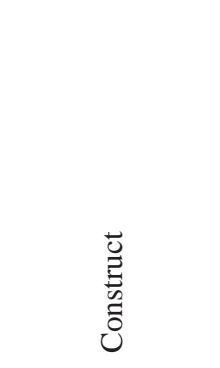 & 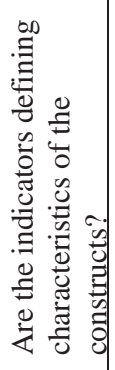 & 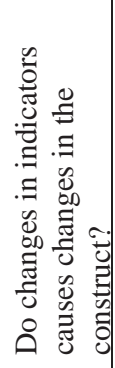 & 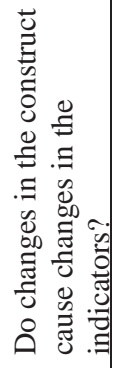 & 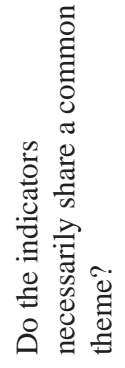 & 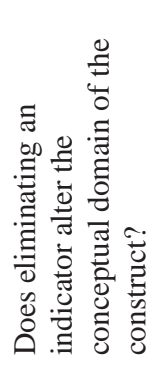 & 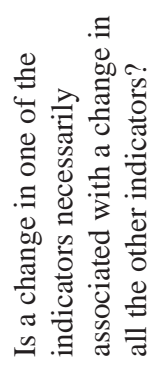 & 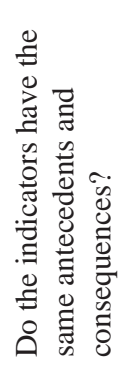 & 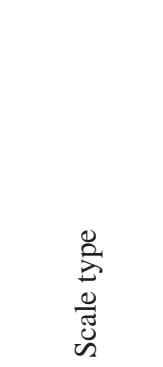 \\
\hline $\begin{array}{l}\text { Customers' } \\
\text { use of u-CRM } \\
\text { (sense) }\end{array}$ & Yes & Yes & No & Yes & Yes & No & No & Formative \\
\hline $\begin{array}{l}\text { Perceived } \\
\text { (customer) } \\
\text { responsiveness }\end{array}$ & No & No & Yes & Yes & No & Yes & No & Reflective \\
\hline $\begin{array}{l}\text { Customer } \\
\text { satisfaction }\end{array}$ & No & No & Yes & Yes & No & Yes & No & Reflective \\
\hline
\end{tabular}




\begin{tabular}{|c|c|c|}
\hline \multicolumn{3}{|c|}{ Appendix C: Construct Measures } \\
\hline Construct & Items $^{\text {a }}$ & Measure source $^{\text {b }}$ \\
\hline $\begin{array}{l}\text { Customers' use of } \\
\text { u-CRM (surrogate } \\
\text { measure for firms' } \\
\text { customer sensing } \\
\text { capability) }\end{array}$ & $\begin{array}{l}\text { I frequently use this mobile app to....... } \\
\text { find products } \\
\text { prepare my regular grocery shopping list } \\
\text { place orders online } \\
\text { provide comments and feedback } \\
\text { find a store more convenient }\end{array}$ & $\begin{array}{l}\text { (Barki et al. 2007; } \\
\text { Burton-Jones and } \\
\text { Straub 2006; } \\
\text { McLean and Sedera } \\
\text { 2010; Venkatesh et } \\
\text { al. 2008; Venkatesh } \\
\text { et al. 2003) }\end{array}$ \\
\hline $\begin{array}{l}\text { Perceived } \\
\text { responsiveness } \\
\text { (customers' } \\
\text { perspective of } \\
\text { firms' responding } \\
\text { capability) }\end{array}$ & $\begin{array}{l}\text { Woolworths/Coles quickly react to the fundamental } \\
\text { changes in my product requirements by providing } \\
\text { me with relevant customized information } \\
\text { When I browse recipes using the mobile app, } \\
\text { Woolworths/Coles is quick to provide relevant } \\
\text { promotional information for the products required to } \\
\text { make that recipe } \\
\text { When I continue to purchase a new product (e.g. } \\
\text { Baby nappies) repetitively, Woolworths/Coles quick } \\
\text { to respond to it by providing other associated product } \\
\text { information (e.g. other baby products) } \\
\text { Woolworths/Coles, is fast to provide information } \\
\text { about discounts and promotions based on the } \\
\text { products I purchase regularly } \\
\text { Woolworths/Coles, is quick to provide information } \\
\text { on discounts and promotions when I change my } \\
\text { preferred store based on the products I created in my } \\
\text { shopping list } \\
\text { When I pass a nearby Woolworths/Coles store, the } \\
\text { mobile app is able to recognize my physical location } \\
\text { to prompt discounts and promotions on my usual } \\
\text { purchases for the particular store } \\
\text { I can easily find the products required to satisfy my } \\
\text { changing needs using the Woolworths/Coles mobile } \\
\text { app } \\
\text { Woolworths/Coles can easily satisfy my new and } \\
\text { changing needs } \\
\text { The product displayed in the specials section of the } \\
\text { mobile app reflects my specific requirements } \\
\text { Overall the information I regularly receive from } \\
\text { Woolworths/Coles is useful and matches my } \\
\text { preferences }\end{array}$ & $\begin{array}{l}\text { (Jayachandran et al. } \\
\text { 2004; Kohli et al. } \\
\text { 1993; Roberts and } \\
\text { Grover 2012a; } \\
\text { Roberts and Grover } \\
\text { 2012b) }\end{array}$ \\
\hline $\begin{array}{l}\text { Customer } \\
\text { satisfaction }\end{array}$ & $\begin{array}{l}\text { I am satisfied with... } \\
\text { the purchasing products functionality provided by } \\
\text { the app } \\
\text { my overall shopping experience with } \\
\text { Woolworths/Coles }\end{array}$ & $\begin{array}{l}\text { (Bhattacherjee } \\
\text { 2001) }\end{array}$ \\
\hline
\end{tabular}

Note: a 1= Strongly disagree, $7=$ Strongly agree.

b Although we draw our survey items from the well-established measurement constructs from Marketing and IS, we only adapt items that correspond to the conceptual definitions of our constructs. 


\begin{tabular}{|c|c|c|}
\hline \multicolumn{2}{|c|}{ Appendix D: Loading and Cross Loading of Measures } \\
\hline & Perceived Responsiveness & Firm's sensing / customer's use of u-CRM \\
\hline PerRes1 & 0.8614 & 0.7134 \\
\hline PerRes2 & 0.8432 & 0.6739 \\
\hline PerRes3 & 0.7976 & 0.5912 \\
\hline PerRes4 & 0.8629 & 0.6807 \\
\hline PerRes6 & 0.7393 & 0.6036 \\
\hline PerRes7 & 0.8634 & 0.7853 \\
\hline PerRes8 & 0.6726 & 0.6726 \\
\hline PerRes9 & 0.8943 & 0.7375 \\
\hline PerRes10 & 0.8769 & 0.7822 \\
\hline Use1 & 0.6893 & 0.8376 \\
\hline Use2 & 0.5091 & 0.7017 \\
\hline Use3 & 0.6541 & 0.7909 \\
\hline Use4 & 0.6218 & 0.7838 \\
\hline Use5 & 0.7659 & 0.7645 \\
\hline
\end{tabular}

\begin{tabular}{|c|l|l|l|l|}
\hline \multicolumn{4}{|c|}{ Appendix E: Internal Consistency and Discriminant Validity of Constructs } \\
\hline & Composite Reliability & Cronbach's Alpha & PR & S/U \\
\hline Perceived Responsiveness & 0.9556 & 0.9480 & $\mathbf{0 . 6 8 4 9}$ & \\
\hline Sense/Use & 0.8661 & 0.8093 & 0.7630 & $\mathbf{0 . 5 6 4 8}$ \\
\hline
\end{tabular}

